Proceedings of the XXIII Conference on Applied Crystallography, Krynica Zdrój, Poland, September 20-24, 2015

\title{
Structural Studies of Welds in Wear-Resistant Steels
}

\author{
M. Bramowicz ${ }^{a *}$, S. Kulesza ${ }^{b}$, P. LeWAlski ${ }^{a}$ And J. Szatkowski ${ }^{c}$ \\ ${ }^{a}$ University of Warmia and Mazury in Olsztyn, Faculty of Technical Sciences, \\ M. Oczapowskiego 11, 10-719 Olsztyn, Poland \\ ${ }^{b}$ University of Warmia and Mazury in Olsztyn, Faculty of Mathematics and Computer Science, \\ Słoneczna 54, 10-710 Olsztyn, Poland \\ ${ }^{c}$ Nicolaus Copernicus University, Faculty of Physics, Astronomy and Informatics, \\ Grudziądzka 5/7, 87-100 Toruń, Poland
}

\begin{abstract}
The work presents results of the research on changes in microstructural, and mechanical properties of the structural XAR 400 wear-resistant steel caused by the welding procedure. Metallographic and microhardness studies revealed complex microstructure of the welds that turned out to vary with the distance from the weld axis: predominance of the acicular ferrite $(\mathrm{ACF})$ structures in the weld itself, quasi-polygonal ferrite (QPF) crystals with precipitates of troostite $(\mathrm{T})$ in the heat-affected zone, and the bainitic ferrite $(\mathrm{BF})$ structures in the heat-partiallyaffected zone.
\end{abstract}

DOI: 10.12693 /APhysPolA.130.963

PACS/topics: 81.20.Vj, 81.05.Bx

\section{Introduction}

Modern wear-resistant steels (WRS) are fine-grained construction materials intended to work under extreme operating conditions e.g. high surface friction and large dynamic loads. Such alloys belong to low-carbon alloys containing trace amounts of other elements that influence their properties: Mo, V, B, Ti, and Cr improve the hardening capacity, $\mathrm{Nb}$ and $\mathrm{Al}$ cease the grain growth, while reduced content of $\mathrm{P}$ and $\mathrm{S}$ decreases the nil-ductility transition temperature. Apart from that, microalloying elements are also found to form stable and highly dispersed carbides coherent with martensitic phase [1,2]. Dudzinski et al. [2] noted that the maintenance and overall construction properties of this material are in fact hardly known.

Depending on the steel grade, as-delivered WRS steels contain tempered martensite or bainitic structures due to their thermal pretreatment. Workpieces made of WRS are widely used in various wear-exposed structures: excavators, mining and earth-moving machinery, scrap presses, paving moulds, agricultural equipment working in a direct contact with the soil, and others [3-7]. Special attention must be paid when prepared elements are further exposed to heat treatment above the tempering temperature, such as forming of parts of machinery, construction-assembly works etc., because induced structural changes substantially influence mechanical and tribological properties of the material.

Welding is the most common method of joining metals in industry today, and hence mechanical characteristics of the welded joints are crucial to receive the desired properties of the workpiece. Unfortunately, the welding

\footnotetext{
*corresponding author; e-mail: mbramowicz@uwm.edu.pl
}

introduces large temperature gradients so that obtaining weld seams with mechanical properties similar to those of the base metal requires lots of care. Experiments revealed that $R_{m}$ values in welds are $c a .40 \%$ lower than in base material $[8,9]$. However, it is also the edge geometry (beveling, for example) that can detrimentally influence the performance of the welded joints diminishing the diffusion of the heat flux [8]. On the other hand, commercially viable WRS specimens are delivered in the heat-treated form (quenched and/or tempered), and to homogenize the weld microstructure, some kind of thermal post-processing is usually required. After all, having insight into processes occurring right in the weld seam, and in the heat-affected zone (HAZ) the welding process can be largely optimized.

\section{Experimental}

This paper is aimed at studying some material characteristics of the welded joints prepared using $10 \mathrm{~mm}$ thick sheets of XAR 400 steel (ThyssenKrupp). Two squares of welded steel $\left(150 \times 150 \mathrm{~mm}^{2}\right)$ were cut out of $10 \mathrm{~mm}$ thick sheets, and then were beveled alongside each member of a joint (BW $10 \mathrm{~V}$ ) to form a double- $\mathrm{V}$ opening. Conventional MAG 135 multi-run welding in a flat position (PA) was carried out using semi-automatic welding machine (KEMPPI KM 400), ESAB OK AristoRod 69 binding agent, and M21 shielding gas.

Inset in Fig. 1a presents schematic cross-section of obtained multi-run weld, together with directions along which microhardness profiles and X-ray diffraction (XRD) data were measured. Performed tensile test of the weld resulted in the $R_{m}$ value equal to $740 \mathrm{MPa}$, that is well below the yield strength of the base material $(1250 \mathrm{MPa})$. In spite of that, however, the welding appears to comply with general rules, since $R_{m}$ values reported elsewhere $[8,9]$ are even lower. 


\section{Results and discussion}

3.1. Microstructure analysis

Metallographic studies of the weld and interfacial material reveal the presence of three distinct zones: weld zone (WZ), HAZ, and heat-partially-affected zone (HPAZ). Figure 1a shows predominance of acicular ferrite structures $(\mathrm{ACF})$ in the central part of the joint, specific of welded steels of this type, but in places trace amounts of Widmanstatten ferrite (WF) can be spotted as well. Such morphology, described in detail in [10, 11], is common for low-carbon, and low-alloy steel welds. On the other hand, the lack of allotriomorphic ferrite (AF) in the central part of observed cross-section can be due to fast heat diffusion from the weld zone.
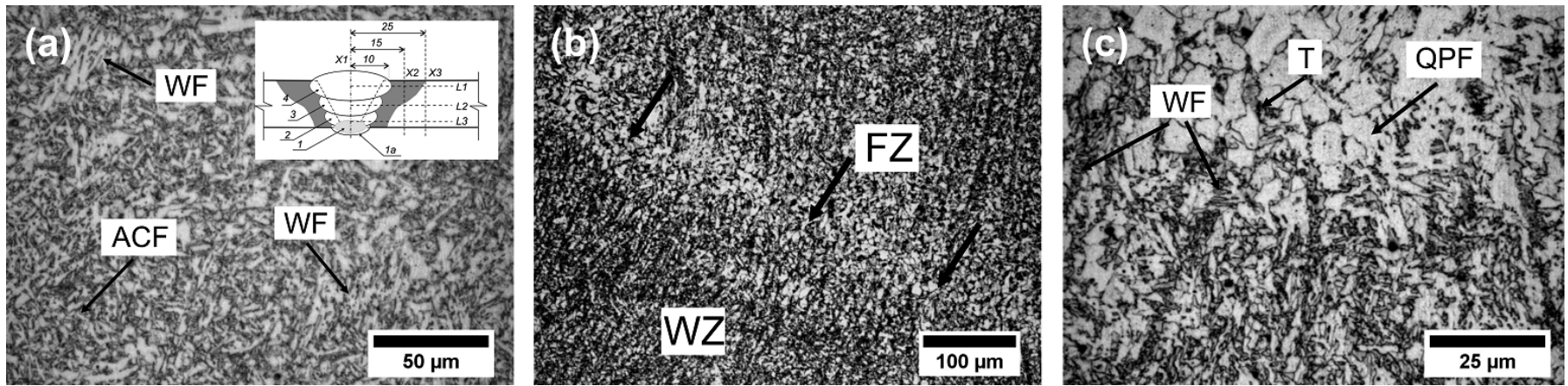

Fig. 1. Metallographic structure of the central part of the cross-section of the weld (a). In the top right corner of (a) schematic cross-section of a multi-run weld joint $(1 \mathrm{a}, 1 \div 4)$. L1, L2, L3 - directions of microhardness profiles. X1, $\mathrm{X} 2, \mathrm{X} 3$ - directions of incident XRD beams. Microstructure of the welded joint in the fusion zone under increased magnification (b), (c).
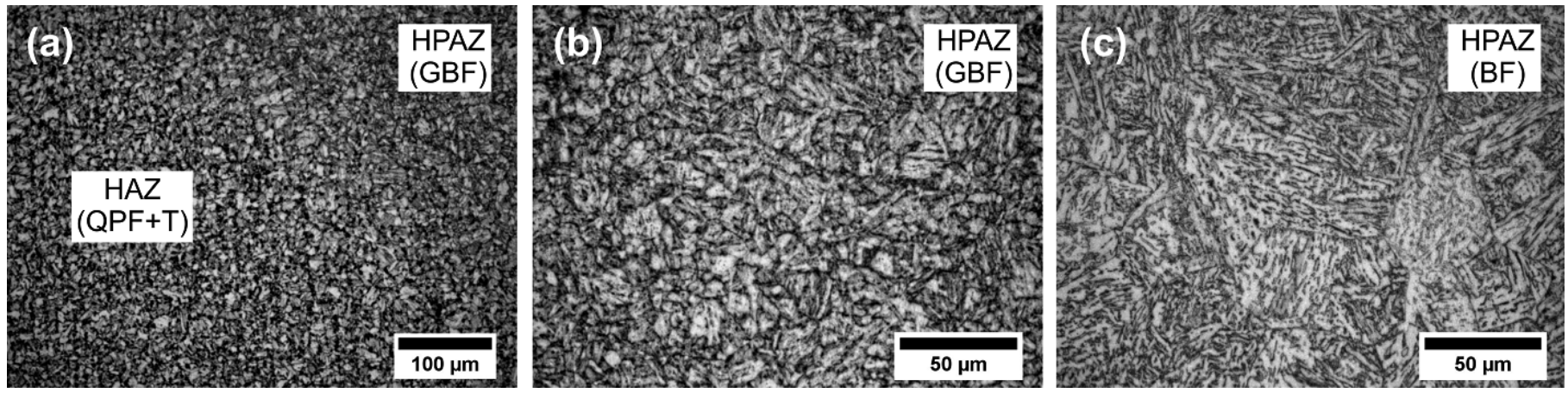

Fig. 2. Microstructure of the weld in the HAZ and HPAZ zones.

Close to the fusion zone (FZ), marked by arrows in Fig. 1b, microstructural morphology shows weld streaks oriented along the direction of temperature gradient, as seen in Fig. 1c. Small grains of ACF are separated by columnar grains of WF, but along the fusion line (FL) the structure is composed mainly of QPFs with insignificant contribution of very fine aggregates of T. Note that geometry of continuous ferrite clusters along the FL corresponds to minimum microhardness numbers HV1 described in the forthcoming paragraph.

Spatial analysis of the cross-section of the weld extending from the fusion line to the base metal reveals further microstructural changes. Close to the FL, complex structure composed of QPF and WF grains is found, but it gradually turns into streaked microstructure composed of $\mathrm{QPF}$ and $\mathrm{T}$ grains close to the base material. Border of the latter structure corresponds to the interface between HAZ and HPAZ zones. Beyond this QPF+T two phase region seen in Fig. 2a, granular bainitic ferrite (GBF) structure appears (Fig. 2a,b) due to influence of lower temperatures, and faster heat out-diffusion, which even further away turns into bainitic ferrite (BF) structure (Fig. 2c).

\section{2. $X R D$ analysis}

X-ray diffraction patterns exhibit body-centered cubic structure with the lattice constant similar to that of $\mathrm{Fe}(\alpha)$, and characteristics of reflection intensities pointing at crystals with $\operatorname{Im} 3 m$ lattice symmetry [12].

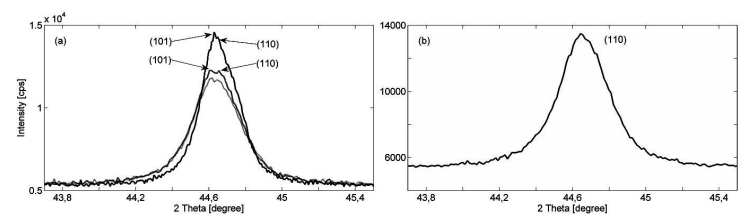

Fig. 3. Low-angle XRD patterns taken from: (a) weld zone and HAZ, (b) base material.

Figure 3 shows that combined effect of narrow-beam, monochromatic X-ray radiation together with small step 
size revealed subtle splitting of $(110)_{\alpha_{c}}$ peak of a cubic phase $\left(\alpha_{c}\right)$ into two peaks: $(101)_{\alpha_{t}}$, and $(110)_{\alpha_{t}}$ of a tetragonal phase $\left(\alpha_{t}\right)$, when passing from base material to the weld axis. Obtained XRD data clearly suggest that in the weld axis, and in the HAZ zone steel forms supersaturated ferrite structure with tetragonal lattice, and tetragonality ( $c / a$ ratio) close to 1 .

\subsection{Microhardness measurements}

Obtained hardness distributions in the cross-section of the weld are presented in Fig. 4. Results suggest that repeated heat treatment caused by subsequent weld runs influence mechanical properties of the material depending on the distance $L$ from the weld axis. As a rule, microhardness values initially decrease approaching minimum described as critical microhardness $\mathrm{Hv}_{c}$ at a length referred to as the critical length $L_{c}$, which corresponds to the border of the FZ composed mostly of QPF structures. Critical lengths measured in $L_{1}, L_{2}, L_{3}$ directions are: 9,7 , and $4 \mathrm{~mm}$, corresponding to $\mathrm{Hv}_{c}$ hardness: 220,213 , and 180 .
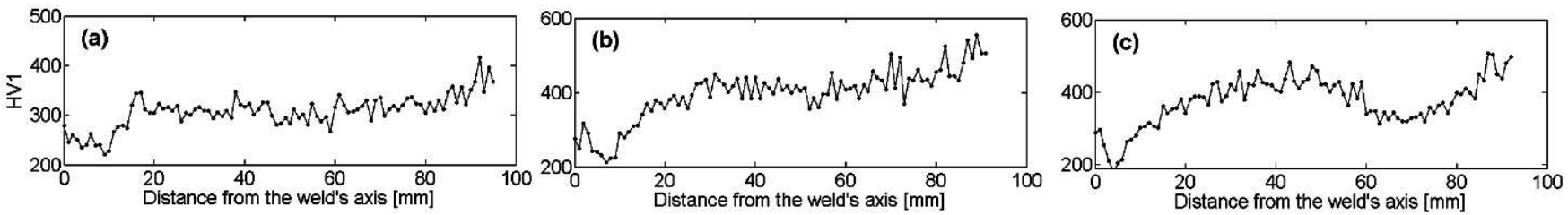

Fig. 4. Cross-sectional Hv1 hardness distribution at various depths from the steel surface: (a) $1 \mathrm{~mm}\left(L_{1}\right)$, (b) $5 \mathrm{~mm}$ $\left(L_{2}\right)$, (c) $9 \mathrm{~mm}\left(L_{3}\right)$.

Figure 4 shows that beyond the critical length microhardness varies in a slightly different way depending on the depth from the surface. Parallel to $L_{1}$ direction, microhardness gradually rises to about $300 \mathrm{Hv} 1$, then follows flat line in the range from 20 to $80 \mathrm{~mm}$, and continues to rise up monotonically to Hv1 value specific of the base material. In turn, microhardness profiles measured along $L_{2}$ and $L_{3}$ lines start to go up soon after the critical length is passed, approach local maximum at about $40 \mathrm{~mm}$ from the origin, then temporarily fall down, but finally turn upwards approaching asymptotically Hv1 microhardness of the base material. Observed increase in Hv1 beyond the critical length can be associated with the formation of supersaturated GBF structure that later turns into BF structure.

\section{Summary}

Presented results on structural changes seen over the cross-section area, and in neighboring zones (HAZ, HPAZ) of the welded joints of WRS, are partly different from observations reported so far. Firstly, the lack of allotriomorphic ferrite (AF) points at rapid heat diffusion from the crystallization zone. Next, performed tensile test gives $R_{m}$ value equal to $740 \mathrm{MPa}$ (i.e. significantly higher than reported in $[8,9]$, but much lower than the base material), which on one hand indicates that the welding procedure ends up with the best possible weld structure, but on the other hand agrees well with the conclusion given in [8] that beveled edges strongly influence mechanical performance of the welded joints. In general, obtained $R_{m}$ equal to $75 \%$ of $R_{p 0.2}$ exhibits detrimental effect of the welding process on the overall strength of the workpiece, and hence must be carefully considered by construction engineers. Obviously, this information should be also provided in the specification of the material. What is worse, changes observed in the weld structure, and in the HAZ, HPAZ due to the welding process substantially reduce the hardness of the studied specimen, which in the FZ decreases by half compared with the base material. As a result, abrasion resistance of the steel is deteriorated locally, which might develop serious failures in wear-exposed, welded structures, such as: large containers, heavy construction equipment etc.

\section{References}

[1] S. Frydman, G. Pekalski, Machin. Technol. Mater. 4-5, 45 (2010).

[2] W. Dudzinski, L. Konat, G. Pekalski, Archiv. Foundry Eng. 8, 21 (2008).

[3] H.-H. Khoo, Ch. Clifton, J. Butterworth, G. MacRae, G. Ferguson, J. Construct. Steel Res. 72, 119 (2012).

[4] G. Anagnostides, A.C. Hargreaves, T.A. Wyatt, J. Construct. Steel Res. 13, 317 (1989).

[5] S. Balos, V. Grabulov, L. Sidjanin, M. Pantic, L. Radisavljevic, Mater. Des. 31, 2916 (2010).

[6] S. Balos, L. Sidjanin, Mater. Des. 32, 4022 (2011).

[7] M. Gwozdzik, Z. Nitkiewicz, Arch. Metall. Mater. 54, 241 (2009).

[8] V. Sharma, A.S. Shahi, Mater. Des. 53, 727 (2014).

[9] S. Frydman, L. Konat, G.P. Kalski, Archiv. Civ. Mech. Eng. 7, 15 (2008).

[10] H.K.D.H. Bhadeshia, L.-E. Svensson, in: Mathematical Modelling of Weld Phenomena, Eds. H. Cerjak, K.E. Easterling, Institute of Materials, London 1993, p. 109.

[11] S.S. Babu, Curr. Opin. Solid State Mater. Sci. 8, 267 (2004).

[12] M. Gwozdzik, Z. Nitkiewicz, Archiv. Metall. Mater. 58, 31 (2013). 